\title{
Systems human factors: how far have we come?
}

\section{Beverley J Norris ${ }^{1,2}$}

The paper by de Korne et al in this issue presents a design solution to an infection control problem in the operating room. Specifically, they sought to achieve consistency in the correct positioning of equipment in the operating room for eye surgeries in order to derive the intended benefits of laminar air flow ventilation in reducing bacterial air contamination.

Korne et al used co-creation between surgical staff and tarmac operators at Schiphol airport and a work analysis to develop a design solution to an issue that had traditionally been approached through training and technical issues. This is an approach firmly rooted in human factors. Many people in healthcare will now be familiar with the term 'human factors', but how far have we come in applying this approach in healthcare?

\section{WHAT PROGRESS HAVE WE MADE?}

One of the earliest references to human factors in the healthcare literature dates back to 1957 and calls for equipment to be designed in terms of human capabilities and limitations. ${ }^{1}$ Presenting data on physical and perceptual abilities (including the effects of excessive cigarette smoke in the cockpit on pilots' performance!) the paper made a plea to the medical community to use the 'principles of human engineering' to

\footnotetext{
${ }^{1}$ National Patient Safety Agency, London, UK; ${ }^{2}$ Helen Hamlyn Centre for Design, Royal College of Art, London, UK

Correspondence to Beverley Norris, National Patient Safety Agency, 4-8 Maple Street, London W1T 5HD, UK; beverley.norris@npsa.nhs.uk
}

improve safety. We now hear of human factors being used to design better medical devices, equipment and information systems, ${ }^{23}$ but this is an exception rather than the rule. Nearly 40 years later, in 1995, authors such as James Reason broadened the meaning of human factors to include cognitive functioning, classifications of human error and active versus latent failures. ${ }^{4}$ These concepts have underpinned a whole raft of patient safety initiatives, focused particularly on improving teamwork, communication and safety culture. ${ }^{56}$

In other industries, however, human factors is used much more at the system design level; workplace design, the design of tasks, processes, equipment and information sources are designed to help staff work safely and effectively.

Korne illustrates this systems approach. The positioning of theatre equipment is vital for the effectiveness of the laminar air flow system, yet previous work on its efficacy had focused on technical issues. A human factors approach would posit that technical efficacy will be redundant if equipment is not used in the right way. Shared learning with safety teams in other industries highlighted that the safety critical positioning of equipment could be more effectively supported by workplace design, than by training or reliance on staff to estimate correct positioning. An analysis of work processes and workplace layout identified floor marking as a potential solution. User input to the designs was vital, as effective design can only be developed if those with a close understanding of the job are consulted. This also enables ownership of the solutions, and feedback from surgical staff during evaluations was vital to the final design.

\section{THE ROLE OF TRAINING}

As Korne points out, design is often easier to change than behaviour. Many in healthcare have been introduced to human factors via human factors training, in many cases based on aviation crew/cockpit resource management (CRM) training. CRM is a system for improving crew performance and concentrates on crewmember attitudes and behaviours. ${ }^{7}$ It supplements many years of human factors input into the design of standardised flight decks, air traffic management systems, maintenance procedures and standardised operating procedures. The level of system design that underpins CRM training in aviation is, of course, less established in healthcare. Training alone would rarely be recommended as a human factors safety solution. It would be part of an overall safety management approach that begins with system analysis and design, using training only for those safety issues that cannot be addressed by the design of safe work practices. ${ }^{8}$

\section{SYSTEMS HUMAN FACTORS}

Human factors interventions are grounded in the principle that all elements of the healthcare system, however far removed from the point of care in space or time, will influence safety. Context must be understood when analysing and designing systems of work. Carayon ${ }^{9}$ demonstrates this with the Systems Engineering Initiative for Patient Safety model. The model provides a simple method for formally considering how system components influence human behaviour, such as issues related to the person, the organisation, technologies and tools, tasks and environment.

The Systems Engineering Initiative for Patient Safety model was used to 
show how considering an array of system factors affected the safety of outpatient surgery and recommendations were made relating to:

- the tasks being undertaken (goaloriented analysis of vital signs monitoring);

- tools of the job (design of the patient's chart);

- environment (noise, open doors);

- organisational design (no single member of staff followed the patient throughout their stay).

The Health and Safety Executive stipulates that 'human factors must be integrated into the mainstream of systems development' ${ }^{10}$ and some industries have incorporated the systems view into formal safety management. Air traffic management has developed a 'human factors case' methodology, based on the safety case approach; before any system changes are implemented, formal assessments are made on issues such as humanmachine interaction, clear roles and responsibilities and communication. ${ }^{11}$ Cost benefit models that prove the effectiveness of such human factors integration approaches have been developed in the military but are yet to be undertaken in healthcare. ${ }^{12}$

Within the systems approach, techniques are available to assess the effect of system components on human behaviour and human error. Techniques such as mental workload assessment, human error identification, hierarchical task analysis are commonplace in other industries yet only occasionally used in healthcare. While many of these techniques have been reported in the healthcare literature, ${ }^{13-15}$ they are yet to be an established part of patient safety management. Some progress has been made in making these methods more accessible for healthcare (such as tailored prospective hazard analysis tools $^{16}$ and device usability assessment techniques ${ }^{17}$ ) but more work is needed to make these tools more widely adopted.

\section{WHERE NEXT FOR HUMAN FACTORS?}

The first step in establishing systems human factors in healthcare is to continue to integrate the work on device usability, human error, teamwork and safety culture into an approach that includes work design and systems analysis. More exemplar projects such as Korne's are needed to demonstrate the potential and value of systems human factors. While improvements in medical device usability often have face validity, the impact of changes to work design can be less apparent and more evidence is needed to show the value of the approach. The underlying principles of human factors such as a systems' view of safety and an inclusive, human centred design process can be applied in nearly all work situations to improve safety. Next steps include the wider application of human factors techniques and integration of human factors into the design, implementation and change management of socio-technical systems in healthcare.

Competing interests None.

Provenance and peer review Commissioned; internally peer reviewed.

BMJ Qual Saf 2012;21:713-714.

doi:10.1136/bmjqs-2011-000476

\section{REFERENCES}

1. McFarland RA. The role of human factors in accidental trauma. Am J Med Sci 1957;234:1-27.

2. Karsh BT, Scanlon M. When is a defibrillator not a defibrillator? When it's like a clock radio.... The challenge of usability and patient safety in the real world. Ann Emerg Med 2007;50:433-5.

3. Lawton R, Gardner P, Green B, et al. An engineered solution to the maladministration of spinal injections. Qual Saf Health Care 2009;18:492-5.

4. Reason J. Understanding adverse events: human factors. Qual Health Care 1995;4:80-9.

5. Tregunno D, Pittini R, Haley M, et al. Development and usability of a behavioural marking system for performance assessment of obstetrical teams. Qual Saf Health Care 2009;18:393-6.

6. Leonard M, Graham S, Bonacum D. The human factor: the critical importance of effective teamwork and communication in providing safe care. Qual Saf Health Care 2004:13(Suppl 1):i85-90.

7. CAP 720, Flight Crew Training: Cockpit Resource Management (CRM) and Line-Oriented Flight Training (LOFT) London: Civil Aviation Authority, ISBN 086039 881. 2002.

8. Hale A, Glendon A. Individual Behaviour in the Control of Danger. Amsterdam: Elsevier, 1987.

9. Carayon P, Schoofs Hundt A, Karsh BT, et al. Work system design for patient safety: the SEIPS model. Qual Saf Health Care 2006;15(Suppl 1):i50-8.

10. Health and Safety Executive. Human Factors Integration: Implementation in the onshore and offshore industries, Research report 001. 2002, ISBN 071762529 X.

11. EUROCONTROL: European Organisation for the Safety of Air Navigation. The Human Factors Case: Guidance for Human Factors Integration. 2004, 040201-08.

12. Cost-Benefit Analysis for Human Factors Integration: A Practical Guide, HFI DTC/ WP 2.7.2/3. Human Factors Integration Defence Technology Centre, 2009.

13. Montague ML, Lee MS, Hussain SS Human error identification: an analysis of myringotomy and ventilation tube insertion. Arch Otolaryngol Head Neck Surg 2004;130:1153-7.

14. Tang B, Hanna GB, Joice $P$, et al. Identification and categorization of technical errors by Observational Clinica Human Reliability Assessment (OCHRA) during laparoscopic cholecystectomy. Arch Surg 2004;139:1215-20.

15. Kennedy PJ, Feingold A, Wiener EL, et al. Analysis of tasks and human factors in anaesthesia for coronary-artery bypass. Anesth Analg 1978;55:374-7.

16. Ward JR, Clarkson PJ, Buckle P, et al. Prospective hazard analysis: tailoring prospective methods to a healthcare context. Research Project PS/035. Patient Safety Research Programme of the Department of Health, 2010.

17. Sawyer D. Do It By Design-An Introduction to Human Factors in Medical Devices. Office of Communication, Education, and Radiation Programs (OCER), 1996, US Food and Drug Administration. 